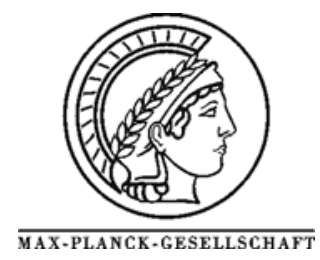

\title{
Morphology-controlled reactivity of carbonaceous materials towards oxidation
}

\author{
J.-O. Müller, D.S. Su*, R.E. Jentoft, J. Kröhnert, F.C. Jentoft, R. Schlögl \\ Department of Inorganic Chemistry, Fritz-Haber-Institute of the MPG, Faradayweg 4-6, 14195 Berlin, Germany \\ ${ }^{*}$ Corresponding author: e-mail dangsheng@fhi-berlin.mpg.de
}

\begin{abstract}
Carbon samples are being investigated with thermogravimetry, infrared spectroscopy and transmission electron microscopy. We focus on a spark discharge soot, soot from a heavy-duty diesel engine, soot from a diesel engine in black smoking conditions and a furnace carbon black from Degussa. The aim of this study is to correlate reactivity towards oxygen, functional groups and nanostructure. It is found that the amount of defects as well as the functionalisation plays an important role in the onset of combustion in the thermogravimetric experiments. Clear differences in reactivity towards oxidation are observed.
\end{abstract}

Keywords: Soot; Reactivity; Microstructure; Functionalisation; TG/TPO; TEM/HRTEM; DRIFTS

\section{Introduction}

In the recent years, efforts to link microstructure of carbonaceous materials and their catalytic activity have been taken in order to improve their role in heterogeneous catalysis [1] and [2]. Great interest has been paid to carbon filaments, nanotubes and fullerenes. The role of carbon as support for catalysts is also subject to investigation [3]. Here, we study the oxidation behaviour and micromorphology of disordered $\mathrm{sp}^{2}$ carbon materials, with a focus on soot from heavy-duty diesel engines. The results are compared with a synthetic soot and a common carbon black.

Diesel engine emissions have gained considerable attention due to their health risk and environmental concerns, especially particulate matter and $\mathrm{NO}_{X}$ [4]. The physical and structural properties of environmental carbons have been investigated with increasing interest in the recent time [5]. The usual investigations are focussed on catalysed or uncatalysed combustion of the soot or carbon black particulates in various atmospheres [6]. However, the majority of soot oxidation studies have not used electron microscopy for a detailed investigation of microstructure or general morphology. The aim of this study is to show that the investigation of not only chemical properties is important; furthermore, carbonaceous materials show different reactivities due to their physical properties.
In the present study, the reactivity of carbonaceous samples to $\mathrm{O}_{2}$ using thermogravimetry/temperature programmed oxidation (TG/TPO) is examined. We investigated spark-discharge soot ("GfG Soot”), Euro IV heavyduty diesel engine soot ("Euro IV Soot"), soot from a black smoking diesel engine ("BS Soot") and furnace carbon black obtained from Degussa ("Furnace Soot"). The role of $\mathrm{O}_{2}$ and the microstructure in the oxidation of soot are emphasised. Furnace Soot and GfG Soot have been chosen as soot models. In view of practical interest, it is important to validate different soot particles as models in $\mathrm{O}_{2}$-soot-based reactions. The nature of oxygen and hydrogen incorporated as functional groups in the different soot samples is investigated with infrared spectroscopy (DRIFTS). The microstructure of the soot and carbon black materials are investigated with transmission electron microscopy (TEM).

\section{Experimental}

The Euro IV Soot is collected from a heavy-duty test diesel engine (6.9 1 displacement, $228 \mathrm{~kW}$ ) equipped with a double-step-controlled supercharging and externalcontrolled cooled exhaust gas recirculation [7]. The maximal exhaust gas flow at rated speed and full load is $1200 \mathrm{~N}$ $\mathrm{m}^{3} / \mathrm{h}$. This engine is optimised in order to fulfil the Euro IV conditions for heavy-duty trucks [8]. The BS Soot sample 
originates from a test diesel engine operating at $30 \%$ load and artificially adjusted for high soot emission by air throttling and reducing rail pressure (blackening number 5). The Furnace Soot is an industrial carbon black (FW 1) obtained from Degussa.

Spark discharge soot (GfG Soot) is produced with an aerosol generator (GfG 1000, Palas GmbH, Karlsruhe) [9] operated with two graphite electrodes (CRG München, 200 ppm ash), $150 \mathrm{~Hz}$ discharge frequency, and 4 1/min argon carrier gas flow.

For TG measurements, the procedures are as follows: the TG/DSC data is acquired using a Netzsch-STA 449 instrument with $\mathrm{Al}_{2} \mathrm{O}_{3}$ crucibles. The samples are evacuated and the sample chamber is re-filled with $5 \% \mathrm{O}_{2}$ in $\mathrm{N}_{2}$, which is maintained at a total flow rate of $100 \mathrm{ml} / \mathrm{min}$. A heating rate of $5 \mathrm{~K} / \mathrm{min}$ is used. The gas phase products are transferred through heated quartz capillary to a Balzers, Thermostar quadrupol mass spectrometer operated in SIM mode. The only products observed are $\mathrm{CO}_{2}$ (m/e 44-46) and $\mathrm{H}_{2} \mathrm{O}(m / e$ 17-18). The MS signals for $m / e 18$ and $m / e$ 44 are representative of $\mathrm{H}_{2} \mathrm{O}$ and $\mathrm{CO}_{2}$, respectively. The ion currents for these masses are divided by the ion current for $m / e 28$ to compensate for changes in sensitivity of the MS instrument. A background was substracted and the ratio was normalised to the mass of soot. The sample charge used for TG analysis is about $1 \mathrm{mg}$.

In this study, a Philips TEM/STEM CM 200 FEG transmission electron microscope equipped with a fieldemission gun is used to study the morphology and microstructure of the carbonaceous materials. The acceleration voltage is set to $200 \mathrm{kV}$. To avoid any misinterpretation of the image contrast, all investigations are carried out on soot particles without underlying carbon film.

To analyse for functional groups in the carbonaceous materials, IR spectroscopy is applied. The measurements are performed in diffuse reflectance (Graseby-Specac DRIFTS accessory) using a Bruker IFS 66 FT-IR spectrometer.

\section{Results}

\subsection{TG/TPO}

The TG/TPO experiments display the different reactivities of the investigated carbon samples. In Fig.1, one clearly observes the variations in the combustion behaviour of the carbon materials.

The onset temperature of combustion of the GfG Soot is about $200{ }^{\circ} \mathrm{C}$. The soot loses mass, until at $640{ }^{\circ} \mathrm{C}$ it is completely oxidised. The Euro IV Soot shows the beginning of a weight loss at $350{ }^{\circ} \mathrm{C}$ and the oxidation of carbon is finished at $590{ }^{\circ} \mathrm{C}$. No further oxidation is observed at temperatures above $590{ }^{\circ} \mathrm{C}$ The $10 \%$ of the sample remaining at $800{ }^{\circ} \mathrm{C}$ is ash from engine lubricating oil. The BS Soot is less prone to oxidation. It begins to lose mass at 500 ${ }^{\circ} \mathrm{C}$ and the highest rate of oxidation is reached at $660{ }^{\circ} \mathrm{C}$. The combustion is completed $690{ }^{\circ} \mathrm{C}$. The Furnace Soot shows the lowest reactivity towards oxidation. The onset temperature of combustion is $550{ }^{\circ} \mathrm{C}$. The soot is burnt out at $690{ }^{\circ} \mathrm{C}$.

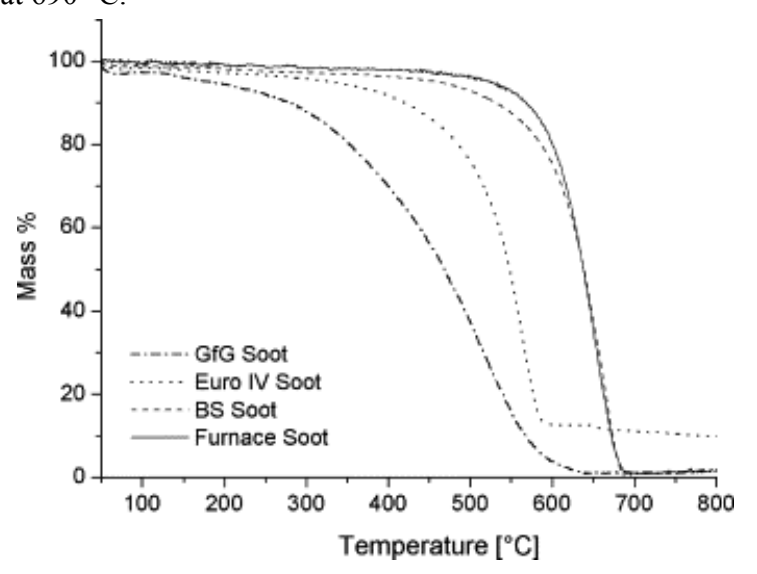

Fig. 1: TG/TPO measurements: mass vs. temperature.

Fig. 2 shows the evolution of $\mathrm{CO}_{2}$ (Fig. 2a) and $\mathrm{H}_{2} \mathrm{O}$ (Fig. 2b) obtained from analysis of the mass spectra. The GfG Soot begins to evolve $\mathrm{CO}_{2}$ at $250{ }^{\circ} \mathrm{C}$. The $\mathrm{CO}_{2}$ evolution shows two maxima, at 340 and $520^{\circ} \mathrm{C}$, respectively.
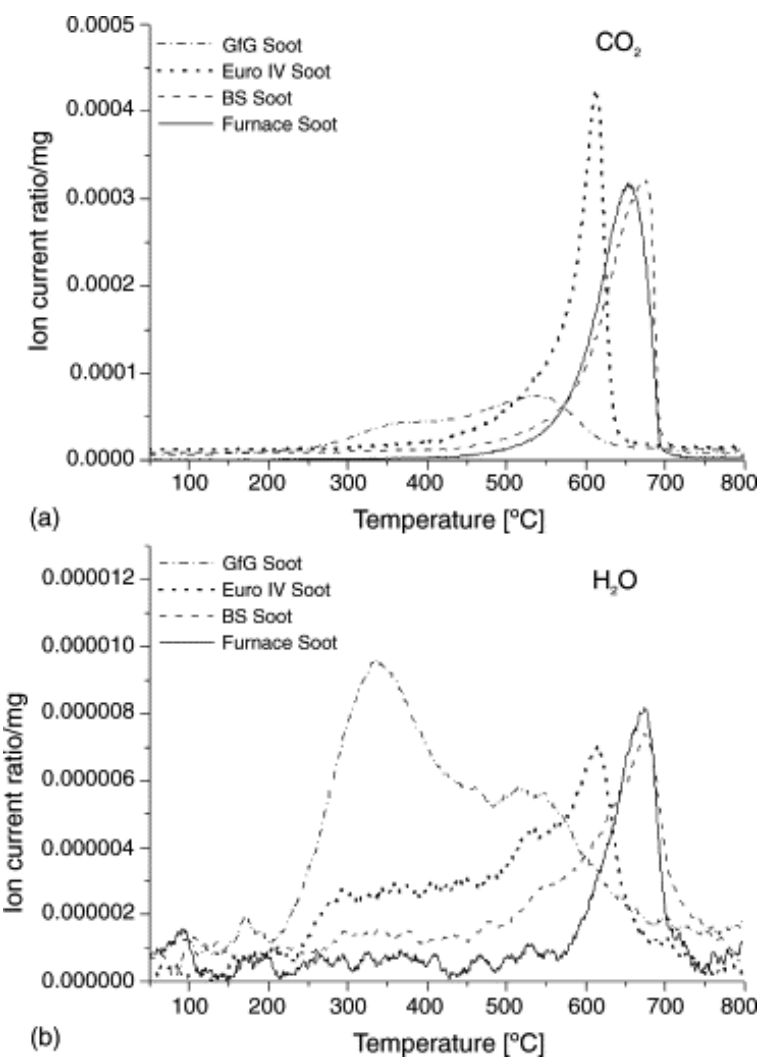

Fig. 2: Mass spectra analysis of the products of combustion (a) $\mathrm{CO}_{2}\left(m / e\right.$ 44) and (b) $\mathrm{H}_{2} \mathrm{O}(m / e$ 18).

The maximum in weight loss occurs at $520{ }^{\circ} \mathrm{C}$. The $\mathrm{H}_{2} \mathrm{O}$ is detected in the effluent stream over the same temperature range as $\mathrm{CO}_{2}$; the maximum in $\mathrm{H}_{2} \mathrm{O}$ evolution is at $340{ }^{\circ} \mathrm{C}$ coinciding with the first maximum in the $\mathrm{CO}_{2}$ signal. A second local maximum in the $\mathrm{H}_{2} \mathrm{O}$ signal is revealed at $520{ }^{\circ} \mathrm{C}$. The MS signal of the Euro IV Soot indicates a slight evolution of $\mathrm{CO}_{2}$ started at above $380{ }^{\circ} \mathrm{C}$. The MS 
signal of $\mathrm{CO}_{2}$ rises rapidly and reaches a maximum at 590 ${ }^{\circ} \mathrm{C}$ corresponding to the maximum of mass loss in the sample. It drops sharply after that due to the total burn out of carbon. The MS spectra of the Euro IV Soot begins to show a $\mathrm{H}_{2} \mathrm{O}$ signal at $250{ }^{\circ} \mathrm{C}$ and shows a shoulder at $300{ }^{\circ} \mathrm{C}$. The maximum in $\mathrm{H}_{2} \mathrm{O}$ evolution $\left(590{ }^{\circ} \mathrm{C}\right)$ corresponds to the maximum in $\mathrm{CO}_{2}$ evolution. The gas phase analysis during the combustion of the BS Soot shows that $\mathrm{CO}_{2}$ begins to evolve at $550{ }^{\circ} \mathrm{C}$ and goes through a maximum at $680{ }^{\circ} \mathrm{C}$. This also corresponds to the maximum in mass loss. A corresponding signal for the evolution of $\mathrm{H}_{2} \mathrm{O}$ from the BS Soot is first detected at $400{ }^{\circ} \mathrm{C}$ with a maximum at $680{ }^{\circ} \mathrm{C}$. The Furnace Soot begins to show a $\mathrm{CO}_{2}$ evolution also at $450{ }^{\circ} \mathrm{C}$, which passes through a maximum at 650 ${ }^{\circ} \mathrm{C}$. An increase of the $\mathrm{H}_{2} \mathrm{O}$ signal occurs at $550{ }^{\circ} \mathrm{C}$, it also has a maximum at $670{ }^{\circ} \mathrm{C}$ corresponding to the maximum in the $\mathrm{CO}_{2}$ signal. The gas phase analysis of the $\mathrm{CO}_{2}$ evolution of the BS Soot and the Furnace Soot is similar, while the $\mathrm{H}_{2} \mathrm{O}$ evolution is different.

It is possible to assign different apparent activation energies to the different soot samples. For this purpose, the samples are heated in the same atmosphere with different heating rates $(1.5,3$ and $5 \mathrm{~K} / \mathrm{min})$. With the model-free analysis suggested by Friedman [10], implemented in the NETZSCH Thermokinetics Diffusion Control software version $2000.9 b$, the apparent activation energies are calculated and summarised in Table 1.

Table 1: Apparent activation energies estimated with model-free analysis of three TPO experiments at 1.5, 3 and $5 \mathrm{~K} / \mathrm{min}$, respectively

\begin{tabular}{llll}
\hline Sample & $\begin{array}{l}\text { Apparent } \\
(\mathbf{k J} / \mathbf{m o l})\end{array}$ & activation & energy \\
\hline GfG Soot & 130 & \\
Euro IV Soot & 160 & \\
BS Soot & 180 & \\
Furnace Soot & 220 & \\
\hline
\end{tabular}

In order to further differentiate the samples, isothermal experiments are conducted at $380{ }^{\circ} \mathrm{C}$, the onset temperature of combustion Euro IV Soot (Fig. 3). One clearly observes the different reactivities of the soot samples. Fig. 3 shows the mass as a function of time for the GfG Soot, the Euro IV Soot, the BS Soot and the Furnace Soot while the samples are kept at $380{ }^{\circ} \mathrm{C}$ for $5 \mathrm{~h}$ in $5 \% \mathrm{O}_{2}$. The GfG Soot loses already $30 \%$ of its mass while heating up to 380 ${ }^{\circ} \mathrm{C}$. The Euro IV and the BS Soot samples lose $3 \%$ of their mass during heating to $320{ }^{\circ} \mathrm{C}$. Between 320 and $380{ }^{\circ} \mathrm{C}$ and for the first $2 \mathrm{~h}$ thereafter, the Euro IV Soot loses weight much more rapidly than the BS Soot. The easiest oxidisable fraction of soot constitutes $8 \%$ of the Euro IV Soot. The Furnace Soot loses during the whole experiment only a small fraction of mass, approximately $3 \%$. After about $4 \mathrm{~h}$ at $380{ }^{\circ} \mathrm{C}$, all the samples continue to lose weight at constant rates, respectively, i.e., the GfG Soot at 5 wt. $\% / h$, the Euro IV Soot at $2 \mathrm{wt} . \% / \mathrm{h}$, the BS Soot at 0.4 wt. $\% / h$ and the Furnace Soot at 0.1 wt. $\% / h$.

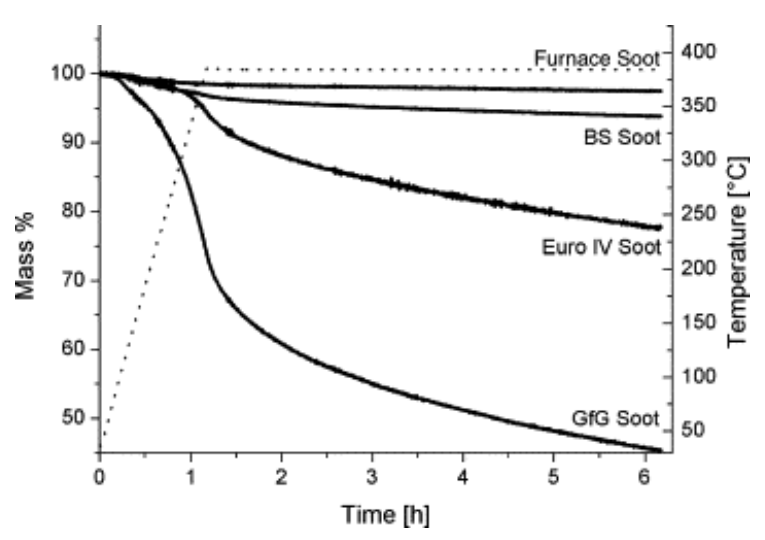

Fig. 3: Isothermal experiments: $6 \mathrm{~h}$ of oxidation for $\mathrm{GfG}$ Soot, Euro IV Soot, BS Soot and Furnace Soot.

\subsection{TEM/HRTEM}

TEM and HRTEM investigations are carried out in order to deduce the microstructure of the different soot materials.

High-resolution images of the GfG Soot reveal very fine agglomerates (Fig. 4a). Spherical particles are not larger than $3 \mathrm{~nm}$ and seldom observed. The graphene segments are strongly bent forming single- or double-layered fullerenoid-like structures, coagulated to long chain-like agglomerates. Graphene rings with a diameter of $1 \mathrm{~nm}$ are observed (arrowed).

The Euro IV Soot shows a different morphology compared to the GfG Soot. The high-resolution electron micrograph (Fig. 4b) shows that the spherical particles are in minority. Small primary particles coagulate to chain-like agglomerates. The agglomerates are built of small nuclei in the size of 10-15 $\mathrm{nm}$. The surface is dominated by irregularities. Small fullerenoid particles with a deformed onionlike structure (2-3 nm in diameter) are observed [11]. A large fraction shows morphology similar to the GfG Soot.

The BS Soot is characterised by a different morphology (Fig. 4c). A disordered core of about 2-3 nm is clearly observed. The outer parts of the spheres are built of homogeneously sized flat basic structural units BSU [12]. The interplanar distances of the graphenes range from 3.4 to $3.5 \AA$, thus being larger than the typical plane distance in graphite (3.362 $\AA$ ). Nanocrystallites consisting of up to four stacked flat graphenes with a size up to $3 \mathrm{~nm}$ can be observed. Some small agglomerates similar to the predominant structures in the Euro IV Soot are observed in the HRTEM micrographs.

The Furnace Soot (Fig. 4d) typically consists of spherical particles with a mean diameter of $25-30 \mathrm{~nm}$. The particles seem larger than those of the Black Smoke (median size of about $25 \mathrm{~nm}$ ); however, the gross morphology is similar. One observes the disordered core and the graphitic outer part of the spherical soot particles. The spherical particles exhibit a very smooth surface with few irregularities. 
(a)
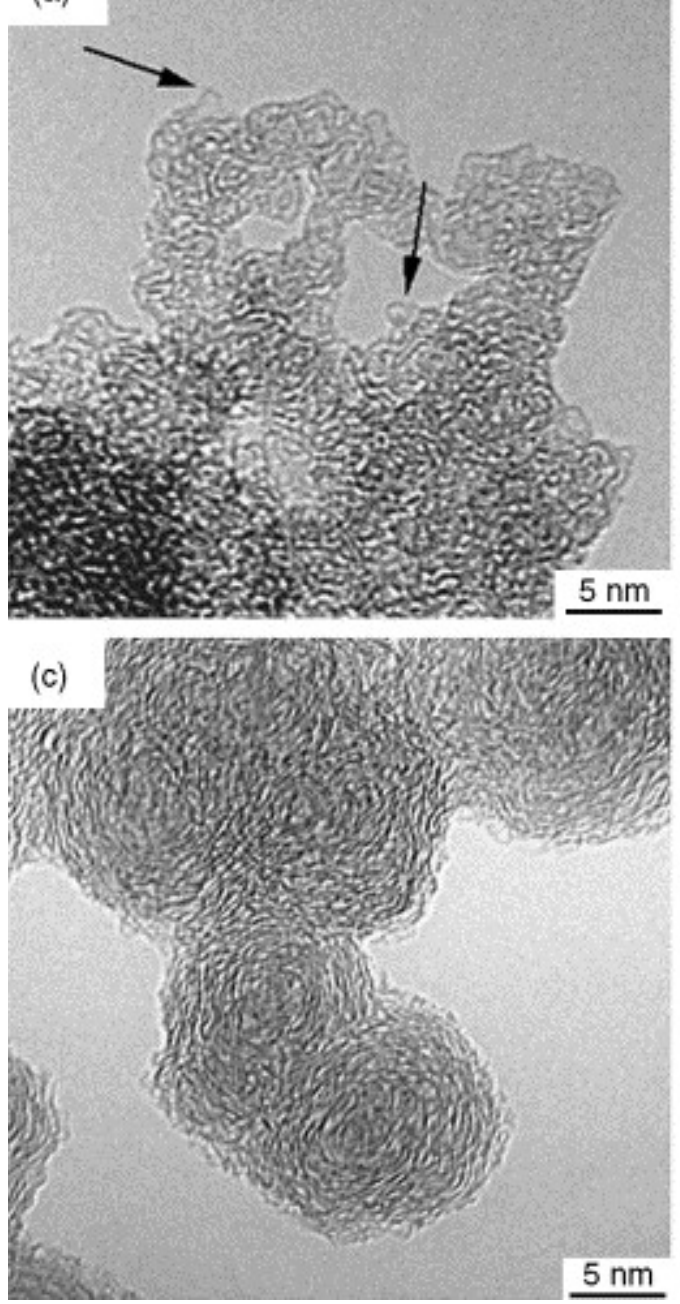

(b)
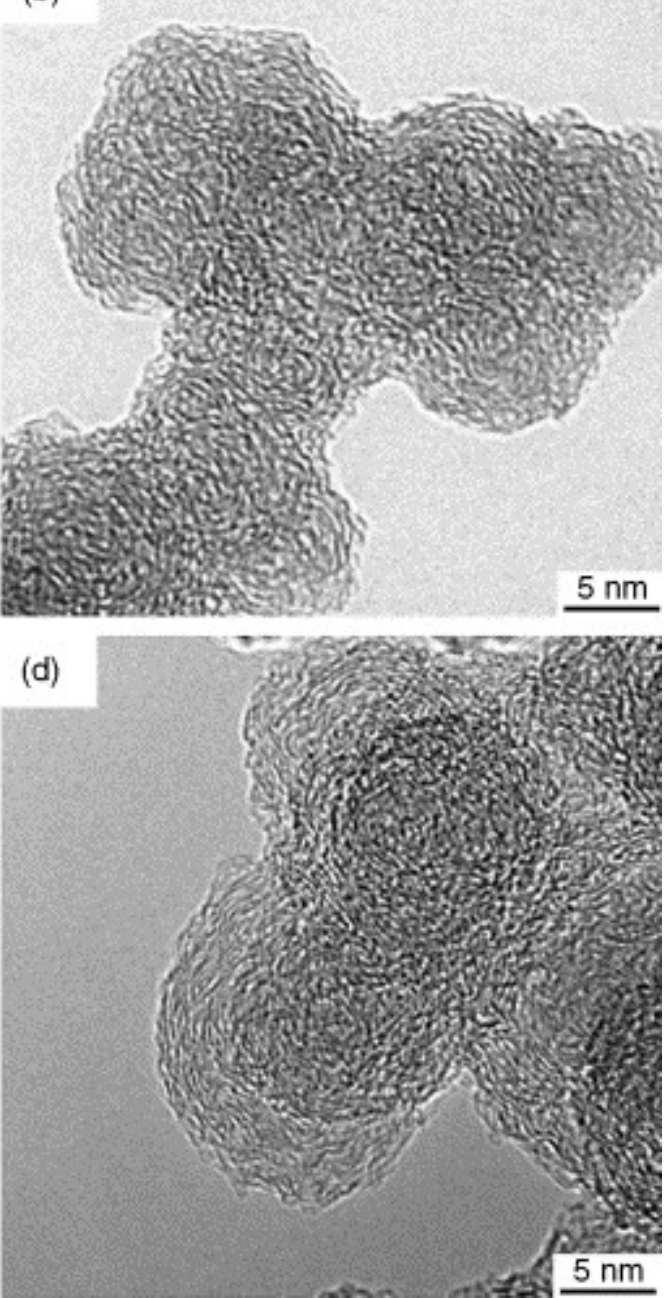

Fig. 4: High-resolution micrographs of (a) GfG Soot, (b) Euro IV Soot, (c) BS Soot and (d) Furnace Soot.

\subsection{DRIFTS}

DRIFTS measurements are carried out in order to investigate the oxygen functional groups. In Fig. 5, the obtained spectra are given. Absorption bands arise at different wavenumbers. The GfG Soot shows the highest reflectivity, possibly due to the finer particles. There is a broad band centred at $3514 \mathrm{~cm}^{-1}$ with two shoulders at 3638 and 3263 $\mathrm{cm}^{-1}$. These features can be assigned to $v(\mathrm{OH})$ vibrations. A weak band at about $3070 \mathrm{~cm}^{-1}$ originates from $\mathrm{C}-\mathrm{H}$ stretching vibrations associated with $\mathrm{C}$ - $\mathrm{C}$ bonds. The bands at 2962, 2932 and $2860 \mathrm{~cm}^{-1}$ are characteristic of the $v(\mathrm{CH})$ vibrations of saturated hydrocarbons, indicating the presence of $\mathrm{sp}^{3}$ hybridised carbon in this sample. The band at $1726 \mathrm{~cm}^{-1}$ represents a $v(\mathrm{CO})$ vibration. The position of this band is relatively characteristic; tables of vibrations of organic compounds point towards an aromatic ester group [13]. Transferred to the soot, this can be interpreted as an ester group attached to the graphenes. The vibration at 1595 $\mathrm{cm}^{-1}$ can be either assigned to the stretching vibration of conjugated $\mathrm{C}=\mathrm{C}$ bonds, or to the bending mode of $\mathrm{H}_{2} \mathrm{O}$.
The broad absorption from 1460 to $1100 \mathrm{~cm}^{-1}$ is difficult to assign in detail. The two shoulders at approx. 1460 and $1390 \mathrm{~cm}^{-1}$ may arise from $\mathrm{C}-\mathrm{H}$ bending vibrations. The broad and intense absorption between 1300 and $1000 \mathrm{~cm}^{-1}$ is assigned to a number of $\mathrm{C}-\mathrm{O}$ vibrations, suggesting the presence of further oxygenates besides esters.

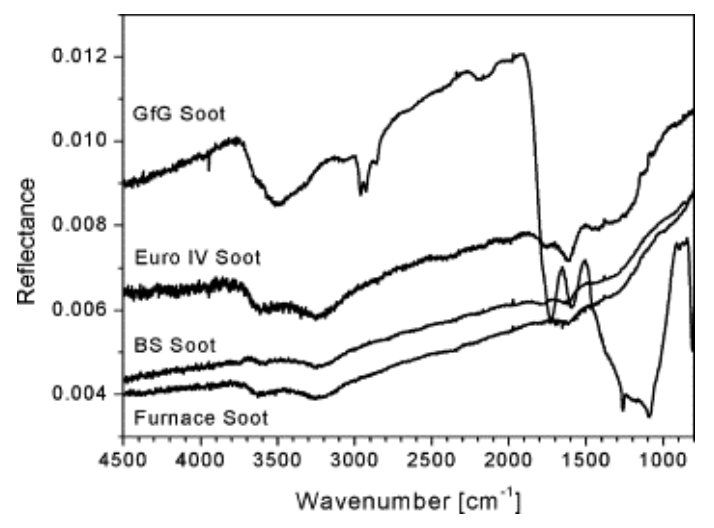

Fig. 5. DRIFTS measurements of the four soot samples. 
Among the structural more similar samples, the spectra of the BS Soot and the Furnace Soot show essentially similar features. The bands at 3600 and $3230 \mathrm{~cm}^{-1}$ can be assigned to $v(\mathrm{OH})$ vibrations. The absorption at 1750 and $1600 \mathrm{~cm}^{-1}$ could be assigned to $\mathrm{C}=\mathrm{O}$ vibrations and $\delta$ $\left(\mathrm{H}_{2} \mathrm{O}\right)$, respectively. The spectrum of the Euro IV Soot contains the spectral features of the BS Soot and the Furnace Soot. However, it is more functionalised than these two samples. The absorption bands at low wavenumbers are more pronounced than those of the BS Soot and the Furnace Soot exhibits. In addition, the spectrum of the Euro IV Soot exhibits a band at $1440 \mathrm{~cm}^{-1}$ indicative of $\delta(\mathrm{CH})$, or more likely $\delta(\mathrm{OH})$, since $v(\mathrm{CH})$ vibrations are absent.

\section{Discussion}

The GfG Soot is the most reactive soot of all the four investigated materials. The reason is the very defective structure, which is observed in the TEM micrographs. The material consists of fine subunits not larger than $3 \mathrm{~nm}$ building up agglomerates with a high surface area. Strongly bent graphenes lead to localised double bonds resulting in an olefinic structure [14]. Theoretical investigations of nanocarbons predict the influence of geometric changes on chemical properties (increasing reactivity upon increasing curvature) [15]. The graphenes in this soot are small as seen in Fig. 4a. This increases the ratio of carbon atoms on graphene edge sites to carbons in the centre of the graphene sheet. A high ratio between border carbon and graphene carbon is equivalent to high reactivity and the carbon is more easily converted to $\mathrm{CO}_{2}$. Carbon atoms in edge sites can form bonds with chemisorbed oxygen and hydrogen due to the availability of unpaired $\mathrm{sp}^{2}$ electrons, while carbon atoms in basal planes are more aromatic having only shared $\pi$-electrons to form chemical bonds [16]. TEM and TPO results are in perfect agreement, as evidenced by the low apparent activation energy that is needed to oxidise the GfG Soot $(130 \mathrm{~kJ} / \mathrm{mol})$. The coordination of the carbons in the defective graphenes must be completed, and this is achieved through functional groups as shown in the DRIFT spectra. Additionally, oxygen containing functional groups attached to non-six-membered rings may occur as very reactive sites [17]. The high reactivity is expressed in an early $\mathrm{CO}_{2}$ evolution starting at $250{ }^{\circ} \mathrm{C}$. The first maximum in the $\mathrm{CO}_{2}$ profile at $340{ }^{\circ} \mathrm{C}$ coincides with a considerable $\mathrm{H}_{2} \mathrm{O}$ evolution, indicating the combustion of the hydrogenrich functional groups. The second maximum in $\mathrm{CO}_{2}$ production (at $520^{\circ} \mathrm{C}$ ) is accompanied by a smaller $\mathrm{H}_{2} \mathrm{O}$ signal and is most likely due to the oxidation of the remaining graphenes.

The Euro IV heavy-duty diesel engine soot is less reactive than the GfG Soot but still more than the BS Soot and the Furnace Soot. The analysis of the apparent activation energy necessary to oxidise the Euro IV Soot results in an intermediate value: $160 \mathrm{~kJ} / \mathrm{mol}$. One reason is seen in the size distribution of primary particles; the majority of the particles have a size of $10-15 \mathrm{~nm}$. Comparing the TEM images, the Euro IV Soot appears more compact and thus, less accessible to oxygen than the GfG Soot. However, the crucial reason is seen in the multi-shell-like fullerenoid structure with the defective surface. The defective non-sixmembered rings may produce, as already described for the GfG Soot, highly localised olefinic electronic structures prone to the addition of molecular oxidants [18]. However, the DRIFT spectra do not reveal $\mathrm{C}-\mathrm{H}$ vibrations as for the GfG Soot but predominantly $\mathrm{C}=\mathrm{O}$ and $\mathrm{O}-\mathrm{H}$ vibrations. As a consequence, the MS-data from the TPO studies show an onset of $\mathrm{H}_{2} \mathrm{O}$ evolution at a lower temperature than the evolution of $\mathrm{CO}_{2}$. Not only the morphology, but also the surface chemistry of the Euro IV Soot differs from that of the GfG Soot.

The BS Soot as well as the Furnace Soot is less prone to oxidation due to the well-developed graphitic properties. The graphenes are flat, indicating a less defective structure. One observes domains where graphenes are stacked forming graphitic nanocrystallites. The ratio of "border" to "in plane" carbons is low. These structures decrease the reactivity [19] and [20]. Additionally, the local density is higher. The higher apparent activation energies, 180 and $220 \mathrm{~kJ} / \mathrm{mol}$, as a result of the TG measurements, are a clear indication of these influences [21]. It is well known that graphite oxidation proceeds anisotropically, i.e., the reactivity of basal plane carbon atoms is far lower than that of edge site carbon atoms. A lower amount of defects should result in fewer functional groups and this is reflected in the DRIFT spectra. However, the spectra do not differ significantly from that of the Euro IV Soot. The MS-data show in the case of the BS Soot a slight $\mathrm{H}_{2} \mathrm{O}$ formation at temperatures around $320^{\circ} \mathrm{C}$. In the case of the Furnace Soot, such a signal is missing.

The general morphology of the soot and carbon black samples reveals drastic differences due to the history of formation. The GfG Soot with its small and strongly bent graphene structures originates from a fast spark-discharge process. The time of formation for aromers or graphenes is thus short. The Euro IV as well as the BS Soot, both are produced in an diesel engine but in considerably different conditions. The conditions of nucleation and growth (supersaturation, temperature) in the carbon-forming volume of the source will determine the abundance of well-ordered particles versus the irregular objects seen in HRTEM. It is observed that the soot morphology is changing with different settings of the test diesel engine (Euro IV conditions). Reduction of rail pressure as well as air throttling leads to significant differences in the soot microstructure, which is not to be explained by changes in load or revolutions per minute of the engine. The formation of carbon black in a furnace is dominated by a long development time in the flame of the furnace. The surface roughness of the particles of the Euro IV Soot is a consequence of the continuous nucleation of new graphene units at the particle, and this process is interrupted by the particle leaving the zone of carbon addition. The smooth outer surface of the particles, as revealed during HRTEM investigations of the BS Soot, and the Furnace Soot indicates a long reaction time to reach 
a minimum energy situation or a post-synthesis oxidative episode that burnt away surface irregularities.

The high rate of oxidation of the GfG Soot and the Euro IV Soot is due to the defective graphenes that are more reactive than these of the BS Soot and the Furnace Soot. The TG analysis shows that the fullerene-like soot is easier to oxidise than well-graphitised samples. This morphology/microstructure-controlled reactivity of soot is in agreement with earlier findings in temperatureprogrammed oxidation studies [22], which show that as the concentration of non-six-membered carbon rings with their olefinic electronic structure increases and with the presence of chemically reactive prism edges, nanocarbons with fullerenoid structure become more reactive than the more graphitised technical carbon blacks.

The reactivity of the small fullerene-like soot originating from the heavy-duty test diesel engine optimised to fulfil the Euro IV conditions may have consequences for the future development of exhaust treatment systems. Certainly, the reduction of particle size is undesirable due to potentially easier access of the fine particles to human lung membranes. However, it seems that from the physicochemical point of view the formation of fullerene-like soot in optimised diesel engines is an indicator of the improvement in diesel engine combustion systems. The small particle size, highly defective surface structure, and more easily oxidised fullerene-like soot identified in this work are prerequisites for the catalytic automotive pollution control.

\section{References}

[1] F. Rodriguez-Reinoso, The role of carbon materials in heterogeneous catalysis, Carbon 36 (1998), p. 159.

[2] P. Serp, M. Corrias and P. Kalck, Carbon nanotubes and nanofibers in catalysis, Appl. Catal. A 253 (2003), p. 337.

[3] E. Auer, A. Freund, J. Pietsch and T. Tacke, Carbons as supports for industrial precious metal catalysts, Appl. Catal. A 173 (1998), p. 259.

[4] U.S.E.P.A. Health assessment document for diesel engine exhaust. Prepared by the National Center for Environmental Assessment, Washington, DC, for the Office of Transportation and Air Quality; EPA/600/8-90/057F. Available from: National Technical Information Service, Springfield, VA; PB2002-107661, and http://www.epa.gov /ncea, 2002.

[5] E. Wichmann, Abschätzung positiver gesundheitlicher Auswirkungen durch den Einsatz von Partikelfiltern bei Dieselfahrzeugen in Deutschland, Im Auftrag des Umweltbundesamtes, Berlin, 2003.

[6] B.R. Stanmore, J.F. Brilhac and P. Gilot, The oxidation of soot: a review of experiments, mechanisms and models, Carbon 39 (2001), p. 2247

[7] E. Jacob, D. Rothe, R. Schlögl, D.S. Su, J.-O. Müller, R. Nießner, C. Adelhelm, A. Messerer, U. Pöschl, K. Müllen, C. Simpson, Z. Tomovic, Dieselruß: Mikrostruktur und Oxidationskinetik, H.P. Lenz (Hrsg.) 24. Internationales Wiener Motorensymposium, 15-16 Mai 2003. Band 2: FortschrittBerichte VDI Reihe 12 Nr. 539 Düsseldorf: VDI-Verlag (2003) 19-45.

[8] (http://www.dieselnet.com)

[9] C. Helsper, W. Mölter, F. Löffler, C. Wadenpohl, S. Kaufmann and G. Wenninger, Investigations of a new aerosol
The choice of adequate model carbon systems is crucial for the understanding of the reactivity of the carbonaceous materials.

\section{Conclusion}

The defective carbons as the GfG Soot and the Euro IV Soot oxidise faster than the well-graphitised soot samples (BS Soot and Furnace Soot). This can be correlated with the micromorphology and the functionalisation of the soot materials. The fact that soot from modern Euro IV diesel engines is more easily oxidised might give new impulses for exhaust treatment technologies. One also has to be aware that model soot substances have to be carefully chosen and investigated for any future development.

\section{Acknowledgements}

This work is part of the project "Katalytisches System zur filterlosen kontinuierlichen Rußpartikelverminderung für Fahrzeugdieselmotoren" supported by the Bayerische Forschungsstiftung and performed in the framework of EL-CASS. The authors thank A. Messerer from the TU Munich, D. Rothe and Dr. E. Jacob from MAN Nutzfahrzeuge AG for providing soot samples.

generator for the production of carbon aggregate particles, Atmos. Environ. 27A (1993), p. 1271.

[10] H.L. Friedman, New methods for evaluating kinetic parameters from thermal analysis data, J. Polym. Sci. Part B: Polym. Lett. 7 (1969), p. 41.

[11] D.S. Su, J.-O. Müller, R.E. Jentoft, D. Rothe, E. Jacob and R. Schlögl, Fullerene-like soot from Euro IV diesel engine: consequences for catalytic automotive pollution control, Top. Catal. 30/31 (2004), p. 241.

[12] A. Oberlin, High resolution TEM studies of carbonization and graphitization. In: P. Thrower, Editor, Chemistry and Physics of Carbon 22, Dekker, New York (1989).

[13] M. Hesse, H. Meier and B. Zeeh, Spektroskopische Methoden in der organischen Chemie, Georg Thieme Verlag, Stuttgart, New York (1984).

[14] M.S. Dresselhaus, G. Dresselhaus and P. Eklund, Science of Fullerenes and Carbon Nanotubes, Academic Press, San Diego (1996).

[15] K. Choho, W. Langenaeker, G. vande Woude and P. Geerlings, Reactivity of fullerenes: Quantum-chemical descriptors versus curvature, J. Mol. Struct. (Theochem.) 338 (1995), p. 293.

[16] R. Schlögl, Surface composition and structure of active carbons, in: F.Schüth, K. Sing, J. Weitkamp (Hrsg.) (Eds.), Handbook of Porous Solids, Wiley-VCH, Weinheim, 2002, Ch., pp. 1863-1900.

[17] D.M. Smith and A.R. Chughtai, The surface structure and reactivity of black carbon, Colloids Surf. A 105 (1995), p. 47 
[18] J. Poater, X. Fradera, M. Duran and M. Sola, An insight into the local aromacities of polycyclic aromatic hydrocarbons, Chem. Eur. J. 9 (2003), p. 1113

[19] R.L. vander Wal and A.J. Tomasek, Soot oxidation: dependence upon initial nanostructure, Combust. Flame 132 (2003), p. 1.

[20] R.L. vander Wal and A.J. Tomasek, Soot nanostructure: dependence upon synthesis conditions, Combust. Flame 136 (2004), p. 129.
[21] J.P.A. Neeft, T.X. Nijhuis, E. Smakman, M. Makkee and J.A. Moulijn, Kinetics of the oxidation of diesel soot, Fuel $\mathbf{7 6}$ (1997), p. 1129.

[22] T. Belz and R. Schlögl, Characterization of fullerene soots and carbon arc electrode deposits, Synth. Met. 77 (1996), p. 223. 